\title{
Expanding the knowledge about Leishmania species in wild mammals and dogs in the Brazilian savannah
}

Rebecca Martins Cardoso', Nadjar Nitz Silva Lociks de Araújo², Gustavo Adolfo Sierra Romero', Thaís Tâmara Castro Minuzzi Souza ${ }^{3}$, Ana Gabriela Dietrich ${ }^{3}$, Júnio Donizette Mendes ${ }^{1}$, Marcelo Lima Reis ${ }^{4}$, Jônatas Barbosa Cavalcante Ferreira ${ }^{3}$, Mariana Machado Hecht ${ }^{2}$ and Rodrigo Gurgel-Gonçalves ${ }^{3^{*}}$

\begin{abstract}
Background: Wild, synanthropic and domestic mammals act as hosts and/or reservoirs of several Leishmania spp. Studies on possible reservoirs of Leishmania in different areas are fundamental to understand host-parasite interactions and develop strategies for the surveillance and control of leishmaniasis. In the present study, we evaluated the Leishmania spp. occurrence in mammals in two conservation units and their surroundings in Brasília, Federal District (FD), Brazil.

Methods: Small mammals were captured in Brasília National Park (BNP) and Contagem Biological Reserve (CBR) and dogs were sampled in residential areas in their vicinity. Skin and blood samples were evaluated by PCR using different molecular markers (D7 24Sa rRNA and rDNA ITS1). Leishmania species were identified by sequencing of PCR products. Dog blood samples were subjected to the rapid immunochromatographic test (DPP) for detection of anti-Leishmania infantum antibodies.

Results: 179 wild mammals were studied and 20.1\% had Leishmania DNA successfully detected in at least one sample. Six mammal species were considered infected: Clyomys laticeps, Necromys lasiurus, Nectomys rattus, Rhipidomys macrurus, Didelphis albiventris and Gracilinanus agilis. No significant difference, comparing the proportion of individuals with Leishmania spp., was observed between the sampled areas and wild mammal species. Most of the positive samples were collected from the rodent N. lasiurus, infected by L. amazonensis or L. braziliensis. Moreover, infections by Trypanosoma spp. were detected in N. lasiurus and G. agilis. All 19 dog samples were positive by DPP; however, only three (15.8\%) were confirmed by PCR assays. DNA sequences of ITS1 dog amplicons showed $100 \%$ identity with L. infantum sequence.
\end{abstract}

Conclusions: The results suggest the participation of six species of wild mammals in the enzootic transmission of Leishmania spp. in FD. This is the first report of L. amazonensis in N. lasiurus.

Keywords: Leishmania Eco-epidemiology, Reservoirs, Molecular diagnostics, PCR

\section{Background}

The leishmaniasis is caused by more than 20 different protozoan species of the genus Leishmania and constitutes a serious public health problem worldwide [1]. Parasites are transmitted by phlebotomine sand flies which become infected during blood meal on mammalian hosts.

\footnotetext{
* Correspondence: gurgelrg@hotmail.com

${ }^{3}$ Laboratório de Parasitologia Médica e Biologia de Vetores, Faculdade de Medicina, Universidade de Brasília, 70904970, Distrito Federal, Brasília, Brazil Full list of author information is available at the end of the article
}

In Brazil, visceral leishmaniasis ( $\mathrm{VL}$ ) is present in 21 states, while the cutaneous forms of the disease (CL) were described in all states since 2003 [2]. In the Federal District of Brazil (FD), VL transmission began in 2005 in residential areas near forests. Moreover, domestic dogs infected with Leishmania spp. have been registered throughout the FD [3].

Several species of wild, domestic and synanthropic mammals have been recorded as hosts and/or reservoirs of Leishmania spp. in Brazil [4-12]. Currently, it is 
accepted that a reservoir may be one or a complex of species responsible for maintaining the parasite in nature in a given period and space $[13,14]$. The transmission of Leishmania species in the wild still represents a complex enzootic "puzzle", as several links have not been identified [12].

Although dogs are considered the most important domestic reservoirs of L. infantum [15], the role of Didelphis spp. as reservoirs have been suggested and its synanthropic capability could facilitate the connection between wild and peridomestic environments [16-19]. Moreover, many rodent species have been identified as potential reservoirs of L. amazonensis, L. braziliensis and L. infantum, showing competence to maintain these parasites [12].

Molecular characterization of the parasites in wild reservoirs indicates the existence of different transmission cycles, illustrating the complexity of the enzootic Leishmania spp. transmission [12]. Then, studies of Leishmania spp. reservoirs in different areas are fundamental to understand host-parasite interactions and develop strategies for the surveillance and control of leishmaniasis. The identification of Leishmania infection in small mammals could be helpful to define the role of these animals in the transmission cycle.

The Brasília National Park (BNP) and the Contagem Biological Reserve (CBR) are federal conservation units where several species of vectors and potential reservoirs of Leishmania spp. could be present; however, Leishmania spp. enzootic transmission in the Brazilian savannah remains poorly investigated. This study aimed to detect Leishmania species in wild and domestic mammals, living in or near both conservation areas, and explore whether: (1) Leishmania species infecting wild animals at conservation units are the same species infecting domestic dogs in the vicinity; (2) there is significant difference in the frequency of Leishmania spp. among mammal species and between the conservation units surveyed.

\section{Methods}

\section{Study area}

The research was carried out in two conservation units, BNP $\left(15^{\circ} 37^{\prime} 31^{\prime \prime} S ; 47^{\circ} 57^{\prime} 36^{\prime \prime} \mathrm{W}\right)$ and CBR $\left(15^{\circ} 40^{\prime} 25^{\prime \prime} \mathrm{S}\right.$; $\left.47^{\circ} 51^{\prime} 56^{\prime \prime} \mathrm{W}\right)$, and in houses of the surrounding areas, located in the administrative region of Sobradinho, in northern FD. CBR and BNP occupy an area of 3460 and 42389 hectares, respectively. Several phytophysiognomies are present in these conservation units such as grasslands, cerrado sensu stricto and gallery forests [20]. According to the Köppen classification the climate of the region is altitude tropical (CWa and $\mathrm{CWb}$ ), with a cold and dry season (April-September) and a warm and rainy season (October to March). The Lago Oeste is a rural area that borders the BNP. The Grande Colorado is a region in Sobradinho formed by 10 residential areas that borders
CBR, of which two were sampled, Vivendas Bela Vista

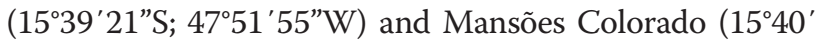
$18^{\prime \prime S} 47^{\circ} 51^{\prime} 21^{\prime \prime}$ ) (Additional file 1: Figure S1).

\section{Animal trapping and sample collection}

Mammal trapping was carried out monthly for four consecutive nights, from November 2011 to July 2012. We performed five field campaigns (Nov, Jan, Mar, May, Jul) in CBR and four (Dec, Feb, Apr, Jul) in BNP. Wild mammals were captured using Sherman and cage traps baited with a mixture of sardines, corn flour, corn, peanut butter and banana. The traps were set every 10 meters on grids in the selected areas. In CBR, we used a grid with eight parallel transects with 21 capture stations each, covering gallery forest and cerrado sensu stricto. In the BNP we used two trap grids, one in the gallery forest, formed by five parallel transects containing 11 capture stations each, and the other in the grassland type vegetation formed by 10 lines, each with 10 capture stations. In the gallery forests of CBR and BNP, the Sherman traps were placed mostly at a height of 1 to $2 \mathrm{~m}$ from the ground.

After capture, animals were sent to a temporary base camp, where they were contained with a combination of ketamine (Agener União, Minas Gerais) and midazolam (Eurofarma Lab. LTDA, São Paulo) at dosages of 10 to $40 \mathrm{mg} / \mathrm{kg}$ and 2 to $4 \mathrm{mg} / \mathrm{kg}$, respectively. Whole blood samples from mammal's retro orbital plexus were collected and transferred to filter paper. Fragments of ear skin were excised and transferred to dry Eppendorf tubes.

Animal identification was performed using taxonomic keys based on external characters [21] and species confirmation was done by a mastozoologist (MLR). Specimens were tagged in the left ear with earrings specific for small mammals (ZT 900, No. 01, $7 \mathrm{~mm}$ ) and released in their capture sites. The material was transported on the same day to the Leishmaniasis Laboratory of the Center for Tropical Medicine at University of Brasília (UnB), where they were kept at $4^{\circ} \mathrm{C}$ (blood) and $-20^{\circ} \mathrm{C}$ (skin) until DNA extraction.

For convenience, dog sampling was performed in two stages. In the first stage, in June 2013, animals that presented Leishmania-positive results in the serological tests conducted by the environmental surveillance service in the Condominium Vivendas Bela Vista (Grande Colorado) were selected. The second sampling was performed in Condominium Mansões Colorado and in the Lago Oeste in September 2013. During the collection, an individual clinical-epidemiological form was filled with the following dog data: name, gender, age, race, color, origin, use of a repellent collar, vaccination, housing and mobility, owner's name and address. Blood samples (3 to $5 \mathrm{~mL}$ ) were collected by venipuncture of the cephalic or femoral vein, which were then transferred to tubes with anticoagulant 
(K3E Vacuette ${ }^{\mathrm{Tw}}$ K3EDTA). After that, $500 \mu \mathrm{L}$ of plasma were collected for serology and $300 \mu \mathrm{L}$ of total blood were used for DNA extraction.

The study was approved by the Ethics Committee on Animal Use (CEUA) Institute of Biological Sciences, University of Brasília (UnBDoC No. 105819/2011) and by the Chico Mendes Institute for Biodiversity ConservationICMBio (authorization $\mathrm{n}^{\circ}$ 29486-4).

\section{Serology}

All dog blood samples were subjected to the rapid chromatographic immunoassay dual path test using the TR DPP $^{\mathrm{ma}}$ (Dual Path Platform) Canine Visceral Leishmaniasis Bio-Manguinhos Kit (Biomanguinhos, Brazil).

\section{PCR and sequencing}

DNA from blood samples was extracted using the Wizard Genomic DNA Purification kit (Promega, USA) and DNA extraction from ear skin fragments was performed using the Illustra tissue \& cells genomic Prep Mini Spin kit (GE Healthcare, USA), according to the manufacturer's instructions. DNA samples obtained from filter papers were extracted as described by Romero et al. [22]. To evaluate endogenous quality and DNA integrity of the samples, PCR was performed for amplification of 800bp fragment of the $\beta$-actin gene by using primers $F W$ 5'-CGG AAC CGC TCA TTG CC-3' and 5'-ACC BW CAC ACT GTG CCC ATC TA -3' [23].

We also amplified the polymorphic region of D7 $24 \mathrm{~S} \alpha$ rRNA gene (primers D75 5'-GCA GAT CTT GGT TGG CGT AG $-3^{\prime}$ and D76 5'-GGT TCT CTG TTG CCC CTT TT $-3^{\prime}$ ) that correspond to conserved sequences of trypanosome genomes, with $\sim 225$-bp fragments suggestive of Leishmania spp. [24,25]. PCR was performed on $25 \mu \mathrm{L}$ volume containing $20 \mathrm{ng} / \mu \mathrm{L}$ DNA, $2.0 \mu \mathrm{M} \mathrm{MgCl}$, $0.2 \mu \mathrm{M}$ dNTPs, $0.2 \mu \mathrm{M}$ of each primer and $1.5 \mathrm{U}$ of Platinum Taq DNA polymerase (Invitrogen, Life Technologies, Brazil). The amplification conditions were described by Schijman et al. [26]. Positive controls used in PCR reactions were obtained from cultures of Trypanosoma cruzi (Berenice strain), T. rangeli (SC-58 strain) and L. (L) infantum (MCER/ BR/1979/M6445). DNA from uninfected Mus musculus reared in the bioterium of the Faculty of Medicine (UnB) was used as negative control. All reactions were performed in a TC-Plus thermocycler (Techne, England, UK) in triplicate. PCR products were analyzed by electrophoresis on $6 \%$ polyacrylamide gel or $2 \%$ agarose gel. Bands with molecular weight of 225-bp were considered positive.

To confirm the positive Leishmania spp. results we used ITS1-PCR with fragments ranging between 302 and 338pb using primers LITS1 5' - CTG GAT TTT GCC CAT ATG - $3^{\prime}$ and L5.85 5' - TCG TGA TAC CAC TTA CAC TT - 3' as described by Schönian et al. [27] and modified by Tojal da Silva et al. [28]. The reactions were prepared in a final volume of $25 \mu \mathrm{L}$ containing $20 \mathrm{ng} / \mu \mathrm{L}$ DNA, 2.0 $\mu \mathrm{M} \mathrm{MgCl}, 0.2 \mu \mathrm{M}$ dNTPs, $0.1 \mu \mathrm{M}$ of each primer and 1.5U of Platinum Taq DNA polymerase (Invitrogen, Life Technologies, Brazil), under the following conditions: $95^{\circ} \mathrm{C}$ for 5 minutes, 35 cycles at $95^{\circ} \mathrm{C}$ for 30 seconds, $58^{\circ} \mathrm{C}$ for 30 seconds, $72^{\circ} \mathrm{C}$ for 30 seconds with a final extension step at $72^{\circ} \mathrm{C}$ for 5 minutes. To increase the sensitivity of the reaction, PCR products were re-amplified with the same primers and the same conditions. All reactions were performed in a TC-Plus thermocycler (Techne, England, UK) in triplicate. Positive controls used in PCR consisted of DNA from cultures of $L$. (L) infantum (MCER/ BR/1979/M6445), L. amazonensis (IFLA/BR/1967/PH8) and L. braziliensis (MHOM/BR/1975/M2904). The specificity of the primers was tested with DNA extracted from uninfected Mus musculus reared in the bioterium of the Faculty of Medicine (UnB). Amplicons were separated on $1.3 \%$ agarose gel.

Amplified fragments were purified using Illustra GFX PCR DNA \& Gel Band Purification Kit (GE Healthcare, New York, USA) and sequenced for identification of the Leishmania species by the companies Genomic Engenharia Molecular (São Paulo, Brazil) and CEGH-CEL (USP - São Paulo, Brazil). Sequences obtained were edited using the Geneious software (Biomatters, New Zealand) and compared with sequences deposited at GenBank using the BLASTn algorithm (Basic Local Alignment Search Tool) at the National Center for Biotechnology Information of the United States of America (http://blast.ncbi. nlm.nih.gov/Blast.cgi). The sequence data were deposited in GenBank (accession numbers KP274860 -KP274863). Fisher exact test was used to compare the proportion of Leishmania-positive individuals between the sampled areas and wild mammal species. Differences were considered statistically significant when $\mathrm{p}<0.05$.

\section{Results}

With a capture effort of 5,840 trap-nights, 183 individuals from 12 species of wild mammals were captured, comprising 86 individuals from 11 species captured in CBR and 97 individuals from eight species captured in the BNP. The most frequent species was Necromys lasiurus (Figure 1a), mainly in cerrado sensu stricto and grasslands. Rhipidomys macrurus (Figure 1b) and Gracilinanus agilis (Figure 1c) were the most frequent species in the gallery forests. The other species were captured in very low proportions $(<6 \%)$ and some were found exclusively in a single area.

PCR was performed in 163 ear skin samples and 156 blood samples of 179 wild mammals, 84 captured at CBR and 95 captured at BNP (Table 1). Four samples were excluded during DNA quality control analyzes. Of the 179 samples studied, $36(20.1 \%)$ were positive for the $24 S \alpha$ 


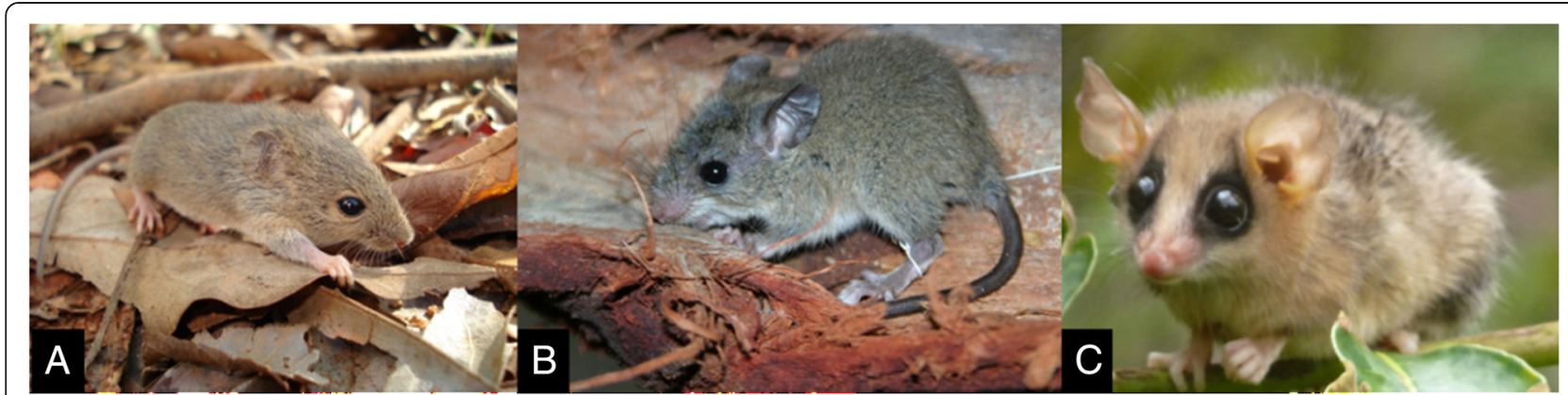

Figure 1 Small mammal species with higher frequency in the study areas. A. Necromys lasiurus, B. Rhipidomys macrurus; C. Gracilinanus agilis.

rRNA gene, showing a fragment of approximately 225-bp, suggesting Leishmania spp., and eight (4.5\%) were positive for ITS1-PCR, confirming the presence of Leishmania spp.

The species showing positive samples were Clyomys laticeps, $N$. lasiurus, Nectomys rattus, $R$. macrurus, Didelphis albiventris and G. agilis. Most of the positive samples were from the rodent $N$. lasiurus (Table 1).

No significant difference was observed when comparing the proportion of individuals with Leishmania spp. between sampled areas and among species ( $\mathrm{p}>0.05)$. Most of wild mammals $(32 / 36)$ showed skin positive results for the $24 \mathrm{~S} \alpha$ rRNA gene; three mammals ( $N$. lasiurus, $G$. agilis and $R$. macrurus) were positive in skin and blood samples. Moreover, 7/8 ITS1 positive samples were

Table 1 Numbers of positive blood and skin samples for the 24Sa rRNA gene of trypanosomatids and for the ITS1 of Leishmania spp. in individuals from conservation units of the Federal District, Brazil

\begin{tabular}{|c|c|c|c|c|c|c|}
\hline \multirow[t]{2}{*}{ Species } & \multicolumn{3}{|c|}{ CBR } & \multicolumn{3}{|c|}{ PNB } \\
\hline & $n$ & 24Sa rRNA & ITS1 & $\mathrm{n}$ & 24Sa rRNA & ITS1 \\
\hline \multicolumn{7}{|l|}{ Rodentia } \\
\hline Necromys lasiurus & 20 & 6 & 1 & 70 & 12 & 2 \\
\hline Nectomys rattus & 8 & 2 & 1 & 2 & 0 & 0 \\
\hline Rhipidomys macrurus & 25 & 7 & 1 & 1 & 0 & 0 \\
\hline Oecomys bicolor & 6 & 0 & 0 & 0 & 0 & 0 \\
\hline Cerradomys scotti & 2 & 0 & 0 & 0 & 0 & 0 \\
\hline Thalpomys lasiotis & 2 & 0 & 0 & 2 & 0 & 0 \\
\hline Calomys sp. & 1 & 0 & 0 & 6 & 0 & 0 \\
\hline Clyomys laticeps & 0 & 0 & 0 & 2 & 1 & 0 \\
\hline \multicolumn{7}{|l|}{ Didelphimorphia } \\
\hline Gracilinanus agilis & 16 & 5 & 2 & 9 & 2 & 1 \\
\hline Didelphis albiventris & 3 & 1 & 0 & 3 & 0 & 0 \\
\hline \multicolumn{7}{|l|}{ Carnivora } \\
\hline Nasua nasua & 1 & 0 & 0 & 0 & 0 & 0 \\
\hline Total & 84 & 21 & 5 & 95 & 15 & 3 \\
\hline
\end{tabular}

detected only in the skin. No individual was positive for ITS1 in both samples simultaneously.

Sampled dogs, 12 males and 7 females, lived exclusively in residential areas. Eleven (58\%) used insecticide impregnated collars and 13 (68\%) were vaccinated against leishmaniasis. Of the 19 dogs, four (21\%) showed clinical signs suggestive of leishmaniasis: weight loss, skin lesions or onychogryphosis. All samples from these dogs were positive in the DPP test. The rRNA $24 S \alpha$ PCR was positive in three (15.8\%) dogs, a result that was confirmed by ITS1-PCR (Additional file 2: Figure S2).

Amplicon sequencing allowed the determination of Leishmania species in the studied areas. ITS1-PCR identified L. infantum in two dogs (No. 2 and 7). L. amazonensis was detected in one $N$. lasiurus captured in the grassland of BNP and L. braziliensis in one $N$. lasiurus captured in the cerrado sensu stricto of CBR. The sequencing of the $24 S \alpha$ rRNA PCR products showed sequences with $89 \%$ identity to $L$. braziliensis obtained from two $R$. macrurus captured in the gallery forest of CBR (Table 2).

Of the 179 individuals, 13 (7.3\%) had samples with fragments of $\sim 240-\mathrm{pb}$ to 290-bp of the $24 \mathrm{~S} \alpha$ rRNA gene, suggesting positive infection by Trypanosoma spp. However, no blood sample was positive to T. cruzi using specific primers TCZ1/2 (data not shown). Sequences analyses of the $24 S \alpha-r R N A$ PCR products of three individuals of $N$. lasiurus showed between 98\% and 99\% identity with $T$. otospermophili and 98\% identity with $T$. kuseli and T. grosi. Moreover, DNA sequence of a $G$. agilis had $91 \%$ identity with $T$. grosi. The sequencing of the ITS1-PCR products of three $N$. lasiurus showed an identity of $79 \%$ and $82 \%$ with $T$. otospermophili. Other specimen of $N$. lasiurus showed $79 \%$ identity with $T$. lewisi.

\section{Discussion}

DNA of three Leishmania species was detected in wild mammals of the conservation units and domestic dogs from the surrounding areas. Of interest, Leishmania species in wild animals within the conservation units (L. amazonensis and L. braziliensis) were not the same 
Table 2 Characteristics of mammals and parasites identified in two conservation units of the Federal District, Brazil

\begin{tabular}{llllllll}
\hline Individual number & Species & Location & Sample & PCR & Blastn & Access number & Identity \\
\hline 2 & C. familiaris & Bela Vista & Blood & ITS1 & L. infantum & gb|KC347301.1 & $313 / 313(100 \%)$ \\
7 & C. familiaris & Bela Vista & Blood & ITS1 & L. infantum & gb|KC347301.1 & $314 / 314(100 \%)$ \\
3 & N. lasiurus & BNP ${ }^{2}$ & Skin & ITS1 & L. amazonensis & gb|FJ753373.1 & $331 / 331(100 \%)$ \\
437 & N. lasiurus & CBR $^{3}$ & Skin & ITS1 & L. braziliensis & gb|FJ753379.1 & $300 / 302(99 \%)$ \\
479 & R. macrurus & CBR & Skin & 24Sa rRNA & L. braziliensis & gb|JX030149.1 & $153 / 171(89 \%)$ \\
481 & R. macrurus & CBR & Skin & 24Sa rRNA & L. braziliensis & gb|JX030097.1 & $153 / 171(89 \%)$ \\
\hline
\end{tabular}

1: Basic Local Alignment Search Tool. 2: Brasília National Park. 3: Contagem Biological Reserve.

from the species detected in domestic dogs (L. infantum). This fact could indicate that i) there are different and independent cycles of Leishmania species in the studied areas; ii) L. infantum has not established yet a sylvatic transmission cycle in the area being maintained by dogs and maybe other synanthropic mammals (e.g. Didelphis albiventris); iii) although the results do not define the reservoir of L. braziliensis in the area, they are sufficient to point out that L. braziliensis includes in its transmission cycle the rodent species $N$. lasiurus. However, sampling effort for dogs was small and we cannot exclude the possibility of L. braziliensis or L. amazonensis circulating within canine population as reported in other endemic areas for these species $[29,30]$.

Dogs have a fundamental role in the domestic cycle of L. infantum because they are highly susceptible to infection, carry an intense, long lasting parasite infection and live in or near human habitations [9,31,32]. Moreover, dogs are proven sources of infection to sand flies due to the abundant amastigotes in their skin which facilitates L. infantum transmission [33]. Wild mammals, however, favor the maintenance of $L$. amazonensis and L. braziliensis in the conservation units. Leishmania amazonensis was identified with $100 \%$ identity in the DNA extracted from the skin sample of one $N$. lasiurus captured in grasslands at the BNP. This is the first record of $L$. amazonensis in this rodent species which shows a wide potential distribution in Brazil [34] and is abundant in open and dry areas of Brazilian savannah [35,36]. Moreover, our data suggest that $R$. macrurus is a possible host of L. braziliensis. Until now, there was only the record of $R$. mastacalis infected with L. infantum in Minas Gerais [10]. The results suggest potential participation of at least six species of different genera of wild mammals in the biological cycle of Leishmania spp. in FD. All these six genera were already associated with Leishmania spp. [7-10,12,37].

The present study focused on wild mammals in conservation units, but there is a need for further studies with synanthropic mammals (e.g. D. albiventris). The role of wild mammals as a source of infection for peridomiciliary vectors should not be ignored [12], since the participation of these mammals in the transmission cycle of L. infantum in urban areas has been proposed [17-19].
Although no statistical difference was detected in the proportion of Leishmania-positive mammals in the different areas, the CBR showed a higher rate of positive samples. CBR has increased anthropogenic influence with the establishment of residential areas around it and with a heavy flow of pets and people within it. Future longitudinal studies analyzing a larger number of mammals and including data of the sand fly infection in these areas may explain the effect of environmental changes in the enzootic transmission of Leishmania.

Necromys lasiurus was the most prevalent mammal species in this study $(50.28 \%)$ with $20 \%$ of the samples positive for the 24S $\alpha$ rRNA gene. This rodent species is considered a potential reservoir because of its role in the maintenance of infection and the potential to transmit the parasite to the vectors $[38,39]$. The infection rate of species ranged from 16.7 to $28 \%$, considering the species with higher number of analyzed samples. However, no significant differences were observed when comparing the proportion of individuals with Leishmania spp. between species. The possibility of at least six species of different genera of wild mammals participating in the biological cycle of Leishmania spp. in the studied areas illustrates the complexity of the enzootic cycles of these parasites. Each host species should have a distinct role in the transmission of Leishmania according to different spatial and temporal scenarios [12]. In this study we present evidence for the association of L. amazonensis with cursorial rodents ( $N$. lasiurus) in grasslands in the $\mathrm{BNP}$ and of $L$. braziliensis with $N$. lasiurus in cerrado sensu stricto in CBR. Future studies including methods that evaluate the parasitaemia and intensity of skin parasitism in these animals using quantitative approaches (qPCR) may reveal whether they are hosts of maintenance or amplification [12,39]. Experimental studies may evaluate the putative role of $N$. lasiurus and $R$. macrurus in the retention of infection and amplification of Leishmania spp., as already observed for other rodent species such as Thrichomys laurentius [40]. In addition, researches on natural infection of sand flies as well as molecular characterization of Leishmania species may provide more data to understand the transmission dynamics in these areas. 
Positive amplification of $24 \mathrm{~S} \alpha$ rRNA suggestive for Leishmania spp. (20.1\%) was similar to the positivity of Leishmania infection in other studies with small mammals $[10,11,37,41]$. However, with more specific primers (ITS1), positivity decreased to $4.5 \%$. Differences in rates of infection with Leishmania spp. among studies may be influenced by methodological differences, such as number and species of mammals sampled, protocols and PCR target used. Amplification of the polymorphic region of the D7 24S $\alpha$ rRNA gene corresponding to conserved sequences of trypanosomatid genomes have different molecular weights to Leishmania spp. and Trypanosoma spp. [24-26] and it is more sensitive when compared to other targets. It is also used for the differential diagnosis of infection by diverse trypanosomes in reservoirs in endemic areas. ITS1-PCR has lower sensitivity compared with the highly abundant target at the kDNA conserved region, as shown in a study by Tojal da Silva et al. [28] with DNA extracted from skin biopsies from humans infected by Leishmania spp. In another study using human and dog blood, the SSU rDNA-PCR was more sensitive than ITS1PCR [28]. However, when nested ITS1-PCR is performed, the sensitivity increases considerably and can match the other targets [27,42].

Our results also demonstrate the presence of Trypanosoma spp. in wild rodents and marsupials in the FD. DNA sequences extracted from samples of four $N$. lasiurus and one G. agilis showed identity ranging from $79-99 \%$ with T. lewisi, T. grosi, T. otospermophili and T. kuseli. Of interest, all of them are rodent trypanosomes [43-46]. Trypanosoma lewisi is a common blood parasite of Rattus spp. in all parts of the world, transmitted by fleas and T. grosi shows a host-restriction to mice of the genus Apodemus, distributed in Europe and Asia [43,44]. Trypanosoma otospermophili and T. kuseli are trypanosomes of squirrels also transmitted by fleas occurring both in old and new worlds $[43,45]$. The identification of these trypanosomes needs confirmation because most samples showed identity values $<90 \%$ and we have no morphological evidence to support these results. It is possible that these trypanosomes belong to other species such as T. forattinii and T. akodoni detected in rodents of the genera Oryzomys and Akodon in Brazil, respectively [43], which are not deposited in GenBank. Although these protozoa are host-specific and not pathogenic to humans, studies show that at least $T$. lewisi can play a role as an opportunistic parasite in humans and captive monkeys [47].

\section{Conclusions}

These results suggest the participation of wild mammals in the cycle of Leishmania spp. in conservation units of the Federal District of Brazil, expanding knowledge on the enzootic cycles of trypanosomatids in the Brazilian savannah. Leishmania species infecting wild animals at conservation units were not the same species infecting domestic dogs in the vicinity. Although no significant differences were observed in the infection rates among mammal species surveyed, the study highlights the role of $N$. lasiurus, $R$. macrurus and G. agilis as hosts of Leishmania spp. However, studies monitoring infection with other parasitological methods (e.g. skin and blood cultures) and sensitive molecular techniques (e.g. qPCR or nested PCR) [42], over a longer period of time including an increased sample size is required to determine whether these mammals meet the established criteria $[48,49]$ to be considered reservoirs of these parasites and evaluate the complexity of host-parasite interactions.

\section{Additional files}

\begin{abstract}
Additional file 1: Figure S1. Study areas in Contagem biological reserve (CBR, cerrado and gallery forests) and Brasilia National Park (BNP, grassland and gallery forests), where small mammals were sampled. Stars show residential areas where dogs were sampled: Lago Oeste (red), Vivendas Bela Vista (green) and Mansões Colorado (yellow). Modified after Unesco [50] and Google earth.

Additional file 2: Figure S2. Identification of Leishmania spp. DNA in dog samples using different molecular markers. Polyacrylamide gel (6\%) showing PCR results. (A) directed to the 24 Sa rRNA gene, with a fragment size of approximately 225-bp, suggestive of Leishmania spp., on canine samples 1 to 19, and (B) ITS1 with a fragment of approximately 310-bp of the canine samples that showed bands with the D75 and D76 primers. MW: molecular weight marker; Positive controls: T. cruzi- Tc, $T$. rangeli- $T r$, L. infantum- Li, L. braziliensis- Lb and L. amazonensis- La; negative control: NC: negative control; WC: White Controls. Red arrows indicate positive samples.
\end{abstract}

\section{Abbreviations}

CRB: Contagem Biological Reserve; PNB: Brasília National Park; PCR: Polymerase Chain Reaction; qPCR: Quantitative real-time PCR; VL: Visceral leishmaniasis; CL: Cutaneous leishmaniasis; FD: Federal District; kDNA: Kinetoplast DNA; DPP: Dual Path Platform..

\section{Competing interests}

The authors declare that they have no competing interest.

\section{Authors' contributions}

RMC, GASR, RGG and NNSLA conceived and designed the study; all authors participated in conducting the study and were involved in the analysis and interpretation of data; RMC wrote the article; RGG, NNSLA GASR reviewed the manuscript; All authors had full access to all data and read and approved the final manuscript.

\section{Acknowledgments}

We thank Ana Maria Jansen, Cesar Augusto Cuba Cuba, Vicente de Paulo Martins and Andrey José de Andrade for reviewing the manuscript. Thanks for José Barbosa Bezerra, Rafael Veríssimo Monteiro, Nárjara Veras Grossmann, Marina Motta de Carvalho, Tauana de Souza Ferreira, Camilla Bernardes Furtado and Renata Ribeiro de Sousa for their help in field and laboratory work. We also thank Juliana Bragança for given us some small mammal's photos. RGG received fellowship from CNPq, Brazil. This research was partially funded by CAPES/Brazilian Ministry of Education.

\section{Funding}

The study was supported by CNPq (141151/2010-2) and CAPES (grant $n^{\circ}$ 1276/11). 


\section{Author details}

${ }^{1}$ Núcleo de Medicina Tropical, Faculdade de Medicina, Universidade de Brasília, 70904970, Distrito Federal, Brasília, Brazil. ²Laboratório Multidisciplinar de Pesquisa em Doença de Chagas, Faculdade de Medicina, Universidade de Brasília, 70904970, Distrito Federal, Brasília, Brazil. 'Laboratório de Parasitologia Médica e Biologia de Vetores, Faculdade de Medicina, Universidade de Brasília, 70904970, Distrito Federal, Brasília, Brazil. ${ }^{4}$ Instituto Chico Mendes de Conservação da Biodiversidade, 70670350, Distrito Federal, Brasília, Brazil.

\section{Received: 17 December 2014 Accepted: 4 March 2015} Published online: 21 March 2015

\section{References}

1. Alvar J, Vélez ID, Bern C, Herrero M, Desjeux P, Cano J, et al. Leishmaniasis worldwide and global estimates of its incidence. PLoS ONE. 2012;7:e35671.

2. Brasil. Ministério da Saúde. Secretaria de Vigilância em Saúde. Departamento de Vigilância Epidemiológica: Atlas de leishmaniose tegumentar americana: diagnósticos clínico e diferencial. 1st ed. Brasília: Editora do Ministério da Saúde; 2006

3. Carranza-Tamayo CO, de Carvalho MDL, Bredt A, Bofil MIR, Rodrigues RMB, da Silva AD, et al. Autochthonous visceral leishmaniasis in Brasilia, Federal District, Brazil. Rev Soc Bras Med Trop. 2010;43:396-9.

4. Deane LM, Deane MP. Observações preliminares sobre a importância comparativa do homem, do cão e da raposa (Lycalopex vetulus) como reservatórios da Leishmania donovani em áreas endêmicas de Calazar, no Ceará. Hospital. 1955;48:61-76.

5. Lainson R, Shaw JJ, Ready PD, Miles MA, Povoa M. Leishmaniasis in Brazil: XVI. Isolation and identification of Leishmania species from sandflies, wild mammals and man in north Para State, with particular reference to $L$. braziliensis guyanensis causative agent of "pian-bois". Trans R Soc Trop Med Hyg. 1981;75:530-6.

6. Lainson R, Shaw JJ. Leishmaniasis in Brazil: I. Observations on enzootic rodent leishmaniasis - incrimination of Lutzomyia flaviscutellata (Mangabeira) as the vector in the lower Amazonian Basin. Trans R Soc Trop Med Hyg. 1968;62:385-95.

7. Brandao-Filho SP, FG D c, de Brito MEF, Almeida FD, Nascimento LA. American cutaneous leishmaniasis in Pernambuco, Brazil - eco-epidemiologic aspects in zona da mata region. Mem Inst Oswaldo Cruz. 1994;89:445-9.

8. Peterson NE, Vexenat JA, Rosa ACOC, Lago PRL. Isolation of Leishmania (Viannia) braziliensis from the rodent Nectomys squamipes captured in Bahia. Brazil Mem Inst Oswaldo Cruz. 1988;83 Suppl 1:28.

9. Dantas-Torres F, Brandão-Filho SP. Visceral leishmaniasis in Brazil: revisiting the paradigms of epidemiology and control. Rev Inst Med Trop Sao Paulo. 2006:48:151-6.

10. Quaresma PF, Rego FD, Botelho HA, da Silva SR, Moura Junior AJ, Teixeira Neto RG, et al. Wild, synanthropic and domestic hosts of Leishmania in an endemic area of cutaneous leishmaniasis in Minas Gerais State, Brazil. Trans R Soc Trop Med Hyg. 2011;105:579-85.

11. Lima BS, Dantas-Torres F, de Carvalho MR, Marinho-Junior JF, de Almeida EL, Brito MEF, et al. Small mammals as hosts of Leishmania spp. in a highly endemic area for zoonotic leishmaniasis in north-eastern Brazil. Trans R Soc Trop Med Hyg. 2013;107:592-7.

12. Roque ALR, Jansen AM. Wild and synanthropic reservoirs of Leishmania species in the Americas. Int J Parasitol Parasites Wildl. 2014;3:251-62.

13. Haydon DT, Cleaveland S, Taylor LH, Laurenson MK. Identifying reservoirs of infection: a conceptual and practical challenge. Emerg Infect Dis. 2002;8:1468-73.

14. Ashford RW. When is a reservoir not a reservoir? Emerg Infect Dis. 2003:9:1495-6.

15. Brasil. Ministério da Saúde. Secretaria de Vigilância em Saúde: Manual de vigilância econtrole da leishmaniose visceral. 1st ed. Brasília: Editora do Ministério da Saúde; 2006

16. Lainson R, Shaw JJ, Lins ZC. Leishmaniasis in Brazil: IV. Fox, Cerdocyon thous $(L)$ as a reservoir of Leishmania-donovani in para-state, Brazil. Trans $R$ Soc Trop Med Hyg. 1969;63:741-5.

17. Santiago ME, Vasconcelos RO, Fattori KR, Munari DP, Michelin AF, Lima VM. An investigation of Leishmania spp. in Didelphis spp. from urban and peri-urban areas in Bauru (São Paulo, Brazil). Vet Parasitol. 2007:150:283-90.

18. Carreira JCA, da Silva AVM, Pereira DD, Brazil RP. Natural infection of Didelphis aurita (Mammalia: Marsupialia) with Leishmania infantum in Brazil. Parasit Vectors. 2012;5:111.
19. Humberg RM, Oshiro ET, Cruz MS, Ribolla PE, Alonso DP, Ferreira AM, et al. Leishmania chagasi in opossums (Didelphis albiventris) in an urban area endemic for visceral leishmaniasis, Campo Grande, Mato Grosso do Sul, Brazil. Am J Trop Med Hyg. 2012;87:470-2.

20. Ribeiro JF, Walter BMT. Fitofisionomias do bioma cerrado. In: Sano SM, Almeida SP, editors. Cerrado: ambiente e flora. Empresa Brasileira de Pesquisa Agropecuária - EMBRAPA/CPAC: Brasília; 1998. p. 89-166.

21. Bonvicino CR, Oliveira JA, D'Andrea OS. Guia dos Roedores do Brasil, com chaves para gêneros baseadas em caracteres externos. Rio de Janeiro: Centro Pan-Americano de Febre Aftosa - OPAS/OMS; 2008.

22. Romero GA, Noronha EF, Pirmez C, Pires Fdo E, Fernandes O, Nehme NS, et al. Sensitivity and reproducibility of a PCR assay for Leishmania detection using skin biopsy imprints on filter paper. Acta Trop. 2009;109:74-7.

23. du Breuil RM, Patel JM, Mendelow BV. Quantitation of beta-actin-specific mRNA transcripts using xeno-competitive PCR. PCR Meth Appl. 1993;3:57-9.

24. Briones MR, Souto RP, Stolf BS, Zingales B. The evolution of two Trypanosoma cruzi subgroups inferred from rRNA genes can be correlated with the interchange of American mammalian faunas in the Cenozoic and has implications to pathogenicity and host specificity. Mol Biochem Parasitol. 1999;104:219-32.

25. Souto RP, Vargas N, Zingales B. Trypanosoma rangeli: discrimination from Trypanosoma cruzi based on a variable domain from the large subunit ribosomal RNA gene. Exp Parasitol. 1999;91:306-14.

26. Schijman AG, Lauricella MA, Marcet PL, Duffy T, Cardinal MV, Bisio M, et al. Differential detection of Blastocrithidia triatomae and Trypanosoma cruzi by amplification of 24salpha ribosomal RNA genes in faeces of sylvatic triatomine species from rural northwestern Argentina. Acta Trop. 2006;99:50-4.

27. Schönian G, Nasereddin A, Dinse N, Schweynoch C, Schallig HD, Presber W, et al. PCR diagnosis and characterization of Leishmania in local and imported clinical samples. Diagnostic Microbiol Infect Dis. 2003;47:349-58.

28. da Silva AC T, Cupolillo E, Volpini AC, Almeida R, Romero GA. Species diversity causing human cutaneous leishmaniasis in Rio Branco, state of Acre, Brazil. Trop Med Int Health. 2006;11:1388-98.

29. Tolezano JE, Uliana SR, Taniguchi HH, Araújo MF, Barbosa JA, Barbosa JE, et al. The first records of Leishmania (Leishmania) amazonensis in dogs (Canis familiaris) diagnosed clinically as having canine visceral leishmaniasis from Araçatuba County, São Paulo State, Brazil. Vet Parasitol. 2007;149:280-4.

30. Oliveira GM, Madeira MF, Oliveira FS, Pacheco RS. PCR associated to molecular hybridization detects Leishmania (Viannia) braziliensis in healthy skin in canine tegumentary leishmaniasis. J Parasitol. 2015;101:91-3.

31. Dantas-Torres $F$. The role of dogs as reservoirs of Leishmania parasites, with emphasis on Leishmania (Leishmania) infantum and Leishmania (Viannia) braziliensis. Vet Parasitol. 2007:149:139-46.

32. Dantas-Torres F. Canine leishmaniasis in South America. Parasit Vectors 2009;2 Suppl 1:S1.

33. Vexenat JA, de Castro JA, Cavalcante R, Tavares JP, da Silva MR, Batista WH, et al. Visceral leishmaniasis in Teresina, State of Piauí, Brazil: preliminary observations on the detection and transmissibility of canine and sandfly infections. Mem Inst Oswaldo Cruz. 1994;89:131-5.

34. Oliveira SV, Escobar LE, Peterson AT, Gurgel-Gonçalves R. Potential geographic distribution of Hantavirus reservoirs in Brazil. PLoS One. 2013;8:e85137.

35. Alho CJ, Souza MJ. Home range and use of space in Zygodontomys lasiurus (Cricetidae, Rodentia) in the Cerrado of central Brazil. Ann Carnegie Mus. 1982;51:127-32

36. Becker RG, Paise G, Baumgarten LC, Vieira EM. Estrutura de comunidades de pequenos Mamíferos e densidade de Necromys lasiurus (Rodentia, Sigmodontinae) em áreas abertas de cerrado no Brasil Central. Mastozool Neotrop. 2007;14:157-68.

37. Brandao-Filho SP, Brito ME, Carvalho FG, Ishikawa EA, Cupolillo E, Floeter-Winter L, et al. Wild and synanthropic hosts of Leishmania (Viannia) braziliensis in the endemic cutaneous leishmaniasis locality of Amaraji, Pernambuco State, Brazil. Trans R Soc Trop Med Hyg. 2003;97:291-6.

38. de Freitas TPT, D’Andrea PS, de Paula DAJ, Nakazato L, Dutra V, Bonvicino CR, et al. Natural infection of Leishmania (Viannia) braziliensis in Mus musculus captured in Mato Grosso, Brazil. Vector Borne Zoonotic Dis. 2012;12:81-3.

39. Jansen AM, Roque ALR. Domestic and wild mammalian reservoirs. In: Telleria J, Tibyarenc M, editors. American Trypanosomiasis - Chagas Disease. London: Elsevier; 2010. p. 249-76.

40. Roque ALR, Cupolillo E, Marchevsky RS, Jansen AM. Thrichomys laurentius (Rodentia; Echimyidae) as a Putative Reservoir of Leishmania infantum and $L$. braziliensis: Patterns of Experimental Infection. PLoS Negl Trop Dis. 2010;4:e589. 
41. Oliveira FS, Pirmez C, Pires MQ, Brazil RP, Pacheco RS. PCR-based diagnosis for detection of Leishmania in skin and blood of rodents from an endemic area of cutaneous and visceral leishmaniasis in Brazil. Vet Parasitol. 2005;129:219-27.

42. Cruz I, Millet A, Carrillo E, Chenik M, Salotra P, Verma S, et al. An approach for interlaboratory comparison of conventional and real-time PCR assays for diagnosis of human leishmaniasis. Exp Parasitol. 2013;134:281-9.

43. Hoare CA. The trypanosomes of mammals. A zoological monograph. Oxford: Blackwell Scientific Publications; 1972.

44. Karbowiak G, Wita I. Trypanosoma (Herpetosoma) grosi kosewiense subsp. n., the Parasite of the Yellow-Necked Mouse Apodemus flavicollis (Melchior, 1834). Acta Protozool. 2004:43:173-8.

45. Sato H, Al-Adhami BH, Une Y, Kamiya H. Trypanosoma (Herpetosoma) kuseli sp. n. (Protozoa: Kinetoplastida) in Siberian flying squirrels (Pteromys volans). Parasitol Res. 2007;101:453-61.

46. Silva FM, Marcili A, Ortiz PA, Epiphanio S, Campaner M, Catão-Dias JL, et al. Phylogenetic, morphological and behavioural analyses support host switching of Trypanosoma (Herpetosoma) lewisi from domestic rats to primates. Infect Genet Evol. 2010;10:522-9.

47. de Sousa MA. On opportunist infections by Trypanosoma lewisi in humans and its differential diagnosis from T. cruzi and T. rangeli. Parasitol Res. 2014;113:4471-5.

48. Silva ES, Gontijo CMF, Melo MN. Contribution of molecular techniques to the epidemiology of neotropical Leishmania species. Trends Parasitol. 2005;21:550-2.

49. Chaves LF, Hernandez MJ, Dobson AP, Pascual M. Sources and sinks: revisiting the criteria for identifying reservoirs for American cutaneous leishmaniasis. Trends Parasitol. 2007;23:311-6.

50. UNESCO. Vegetação no Distrito Federal: tempo e espaço. 1st ed. Brasília: Organização das Nações Unidaspara a Educação, a Ciência e a Cultura UNESCO; 2002.

\section{Submit your next manuscript to BioMed Central and take full advantage of:}

- Convenient online submission

- Thorough peer review

- No space constraints or color figure charges

- Immediate publication on acceptance

- Inclusion in PubMed, CAS, Scopus and Google Scholar

- Research which is freely available for redistribution 